\title{
Analysis of Main Insulation Electric Field of SFPSZ9-150000/220 Power Transformer
}

\author{
Yan $\mathrm{LI}^{1}$, Haoming WANG ${ }^{1, a}$, Longnv $\mathrm{LI}^{1}$, Bo ZHANG ${ }^{1}$, Naisheng LIU \\ ${ }^{1}$ Research Institution of Special Electrical Machines, Shenyang University of Technology, \\ Shenyang, 110870, China \\ aemail: 15931831393@163.com \\ Keywords: power transformer; main insulation; electric field intensity; insulation margin
}

\begin{abstract}
Main insulation electric field of a $220 \mathrm{kV}$ oil-immersed power transformer is calculated. First of all, the main insulation structure is divided into three regions and the corresponding simplified model is established using a two-dimensional axisymmetric calculation field; then typical paths and locations are selected and its field strength and the corresponding insulation margin are mainly examined; finally, the position of the maximum electric field strength and the path of the maximum average electric field strength are obtained by comparing and analyzing the distribution of potential and electric field intensity in different regions, and corresponding insulation margin is calculated which provides an effective method of engineering analysis for reasonable and economical design of the structure of main insulation.
\end{abstract}

\section{Introduction}

With the development of modern electricity and increasingly higher of transformer voltage level, the reasonable design of insulation structure becomes particularly important. Reasonable transformer insulation can guarantee its reliable operation and improve its operating economy, and calculating the distribution of inner electric field is the prerequisite for a more economical and rational design of insulation structure[1]. Through numerical calculation of main insulation electric field of a SFPSZ9-150000 / 220 power transformer in the AC power frequency, the distribution of equipotential lines, field intensity and field vector, and the maximum field strength of the upper, the lower, the middle and its corresponding insulation margin are obtained, providing a reliable basis and effective engineering methods to design insulation structure[2,3].

\section{Simplified model}

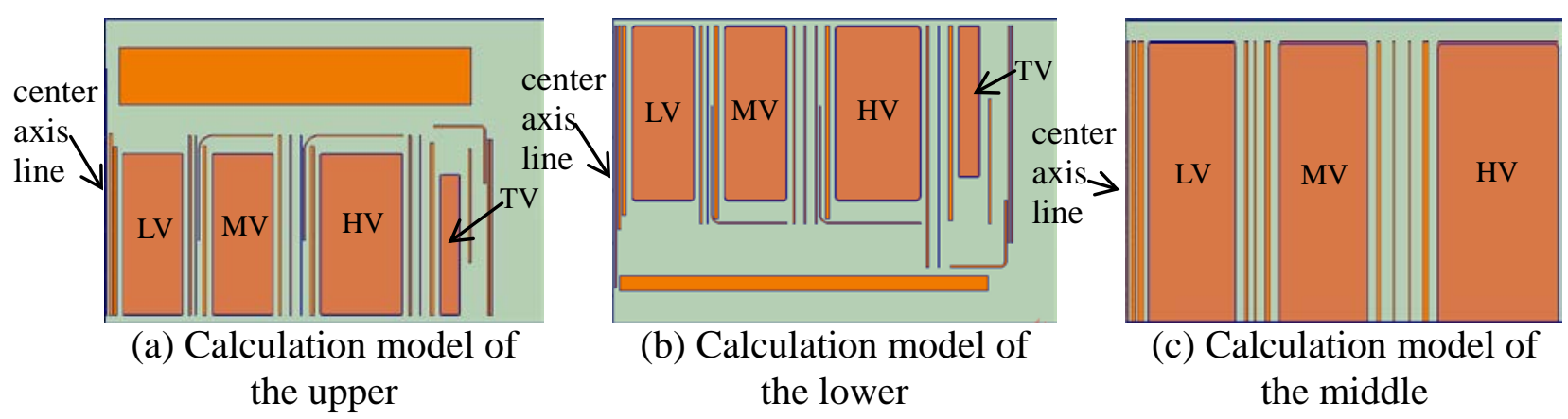

Fig.1. The simplified model

This paper analyzes the SFPSZ9-150000 / 220 transformer which is a three-phase three-winding OLTC power transformer. High voltage (HV) winding with regulator is central outgoing, medium voltage (MV) and low voltage (LV) windings are the end outgoing, rated voltage (220 $\pm 8 \times 1.5 \%)$ /121/38.5kV[4,5]. The main insulated electric field is divided into three parts, respectively the lower, the upper and the middle, calculated by two-dimensional axisymmetric field. The actual model is imported from AutoCAD, which the horizontal axis of left edge is equal to the radius of the core, thus ensuring the core centerline and default rotation axis (y-axis) of ElecNet software coincide. Then the imported model is rotated a certain angle, material properties are assigned (the constant of dielectric of transformer oil, insulating paper and insulating paper tube were taken 2.2, 3.5 and 4.4), 
the boundary conditions are determined and simulation. The simplified calculation model of upper, lower and middle portion are shown in Figure 1.

Based on the above model, the Boundary Value Problems for using the scalar potential $\varphi$ to calculate transformer main insulation electric field are:

$$
\left\{\begin{array}{l}
\nabla \cdot(\varepsilon \nabla \varphi)=0 \\
\Gamma_{1}: \varphi=U_{0}(x, y) \\
\Gamma_{2}: \frac{\partial \varphi}{\partial n}=0 \\
\Gamma_{12}:\left(\varepsilon_{1} \frac{\partial \varphi}{\partial n}\right)^{+}=\left(\varepsilon_{2} \frac{\partial \varphi}{\partial n}\right)^{-}
\end{array}\right.
$$

Where, $\varepsilon, \varepsilon_{1} 、 \varepsilon_{2}$ is permeability, $\mathrm{H} / \mathrm{m} ; \Gamma_{1}$ is the first homogeneous boundary; $\Gamma_{2}$ is the second homogeneous boundary; $\Gamma_{12}$ is the boundary of different media.

According the formula, the left and upper boundary of upper portion, the left and lower boundary of lower portion and the left and right boundary of middle portion are assigned the first homogeneous boundary, while others are the second homogeneous boundary, natural meet[6].

The average electric field strength and insulation margin of ab path are obtained through integrating the electric field strength along the ab direction by equation (2):

$$
\left\{\begin{array}{l}
U_{a b}=\sum_{i=1}^{n} E_{i} l_{i} \\
\bar{E}_{a b}=U_{a b} / \sum_{i=1}^{n} l_{i} \\
q=E_{c p} / \bar{E}_{a b}
\end{array}\right.
$$

Where is $i$ the $i$-th unit from point a to point $b ; l_{i}$ is the length of each unit; $n$ is the total number of units; $q$ is insulation margin; $E_{c p} 、 \bar{E}_{a b}$ is the allowable and average value of the electric field strength respectively.

\section{Calculation and analysis of main insulation electric field}

A. The electric field calculation of the lower end region

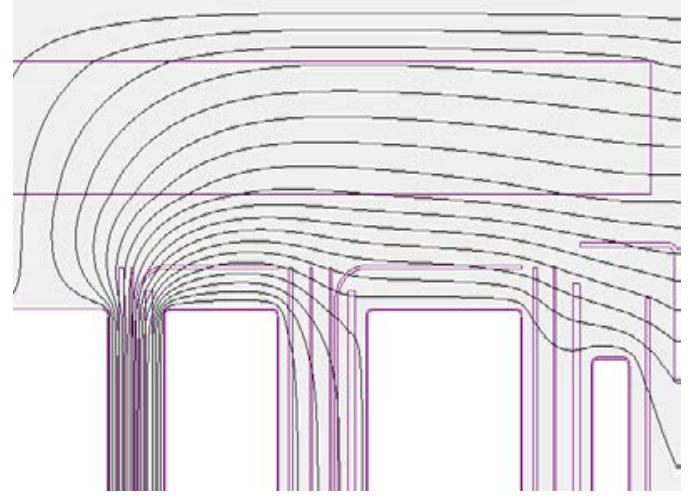

Fig.2. Equipotential distribution of the upper

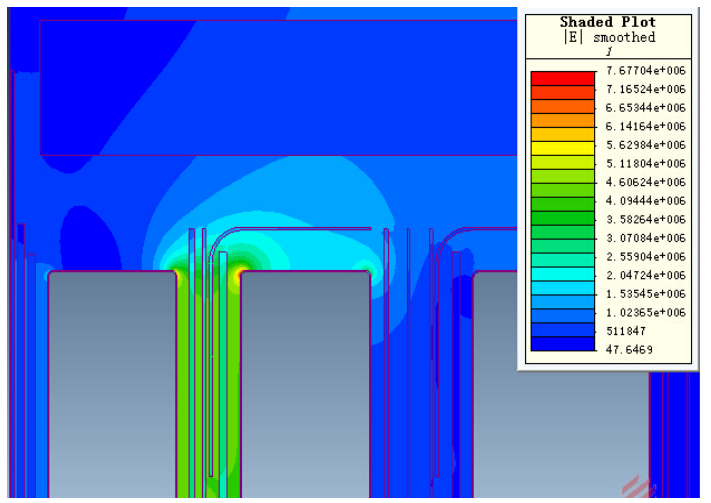

Fig.3. Electric field distribution of the upper

The applied voltage of calculating model of electric field in the upper end including LV, MV, $\mathrm{HV}$ and TV winding are $20 \mathrm{kV}, 200 \mathrm{kV}, 151 \mathrm{kV}$ and $151 \mathrm{kV}$, respectively. End equipotential line and electric field shown in Figure 2 and 3 were calculated by using ElecNet. It can be seen the most concentrated distribution of potential line is at the corner of inner surface of the end of MV winding close to LV where the maximum field strength is $7.68 \mathrm{kV} / \mathrm{mm}$ and it's higher than the lower end. The reasons why the biggest field strength is here are the potential difference applied between MV 
and LV winding of the upper is greater than the lower, and insulation distance between MV and LV wingding is shorter than the distance between $\mathrm{HV}$ and $\mathrm{MV}$ winding. Its insulation margin is $8.5 / 7.68=1.11$, which is smaller than the maximum field strength in the lower end region.

$B$. The electric field calculation of the lower end region

The potential of calculating model of electric field in the lower end region including LV, MV, $\mathrm{HV}$ and TV winding are respectively $0 \mathrm{kV}, 67 \mathrm{kV}, 200 \mathrm{kV}, 132 \mathrm{kV}$. End equipotential line and electric field

Shown in Figure 4 are determined through the model calculated and the electric field intensity vector distribution shown in Figure 5, the distribution of electric field of the selected typical path 1, 2, 3 in the lower end region is shown in Figure 6, and the results illustrated in Figure 7, Figure 8 and Figure 9.

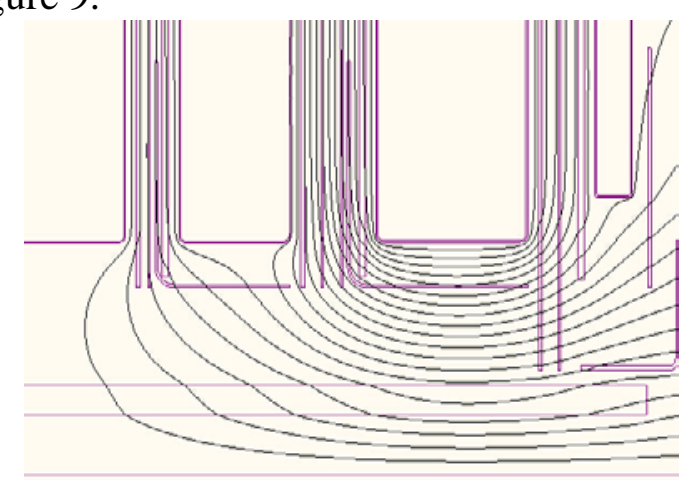

Fig.4. Equipotential distribution of the lower

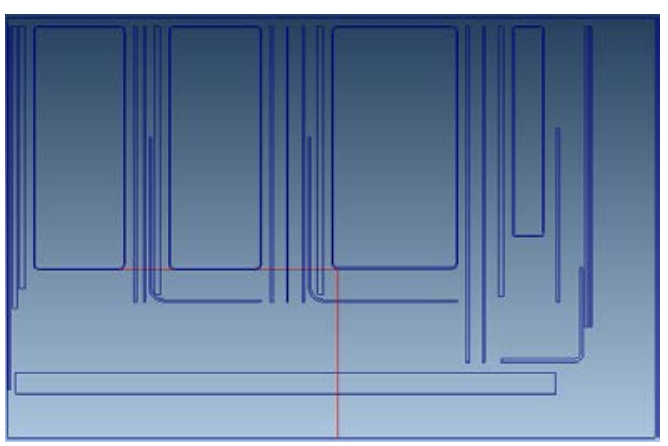

Fig.6. Schematic diagram of typical paths

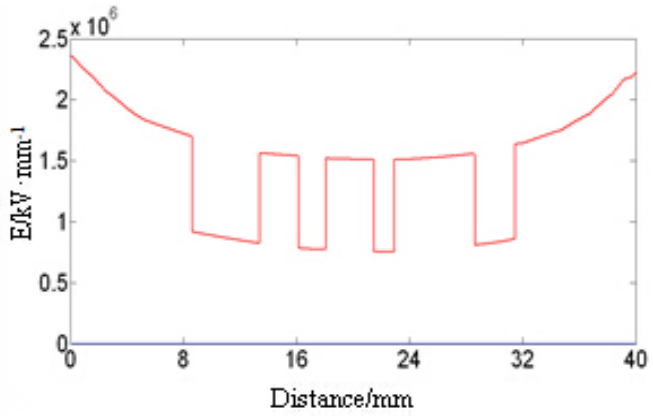

Fig.8. Field strength distribution of path 2 between $\mathrm{HV}$ winding and yoke

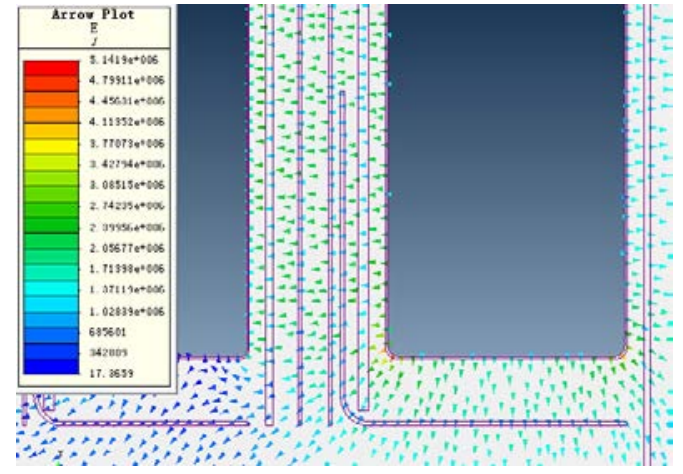

Fig.5. Electric field intensity vector distribution of the lower

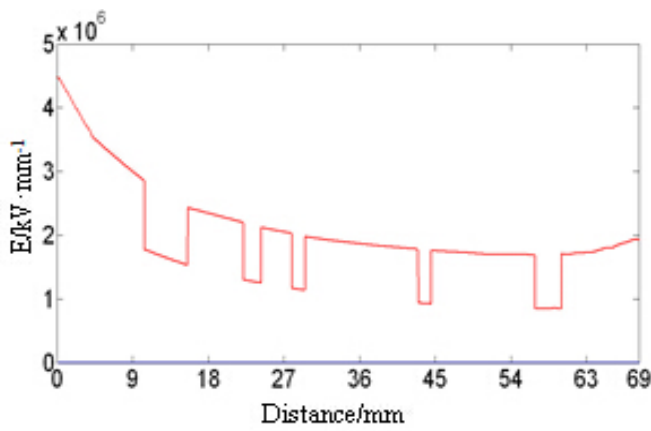

Fig.7. Field strength distribution of path 1 between $\mathrm{HV}$ and MV winding

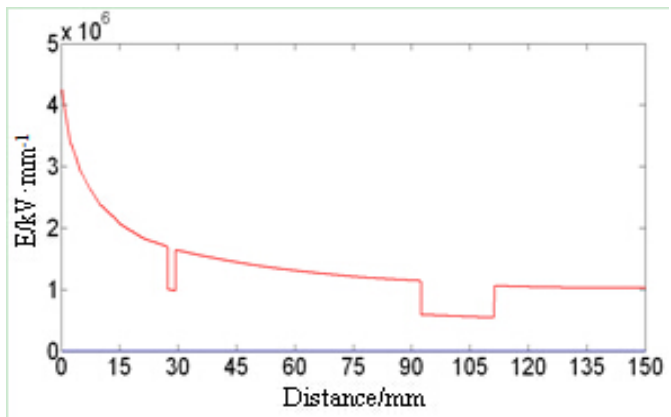

Fig.9. Field strength distribution of path 3 between MV and LV winding

As can be seen from the figures, the point of the highest potential is appeared at the surface of the HV coil, and the most densely potential line is at the corner of the inner surface of $\mathrm{HV}$ coil end near the $\mathrm{MV}$, and the maximum value is about $5.14 \mathrm{kV} / \mathrm{mm}$. And the closer to this position, the more obvious distortion of the electric field strength is. The first oil gap between $\mathrm{HV}$ and MV winding is $8 \mathrm{~mm}$, and its maximum tolerated field strength is $8.5 \mathrm{kV} / \mathrm{mm}$ and insulation margin is $8.5 / 5.14=1.65$. While other oil gaps are all less than $10 \mathrm{~mm}$ and the electric field strength is less than the inner corner of $\mathrm{HV}$ coil end, the insulation margin are larger than 1.65. 
Illustrated in Figure 5, the point of maximum field strength is on the inner surface of HV winding, and distribution along the path 1, the maximum field strength is appeared here, and the maximum field strength obtained from Figure 7 is $4.5 \mathrm{kV} / \mathrm{mm}$. Known from the field strength distribution along the path 2, the maximum field strength is $4.5 \mathrm{kV} / \mathrm{mm}$. On the path 3 , the maximum field strength lied in the corner of the inner surface of MV winding is $2.5 \mathrm{kV} / \mathrm{mm}$ and coincide the value shown in Figure 5.

$C$. The electric field calculation of the middle

In the central electric field, the electric potential of $\mathrm{LV}$ winding is $10 \mathrm{kV}$, the electric potential of MV winding is $133 \mathrm{kV}$ and $\mathrm{HV}$ winding of the terminal voltage is $395 \mathrm{kV}$, the distribution of the electric field can be shown as Figure 10 and Figure 11.

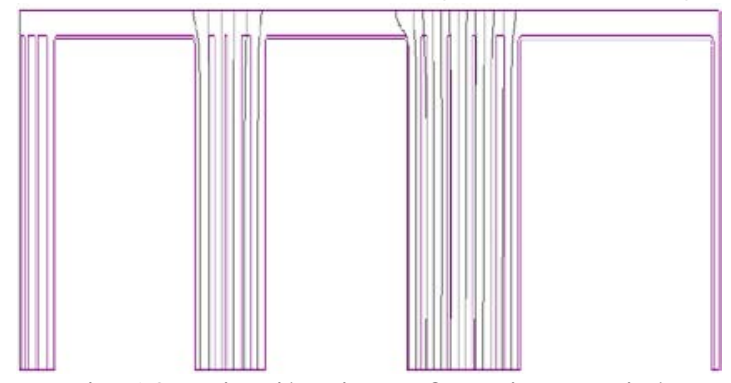

Fig.10. Distribution of equipotential lines in the middle part

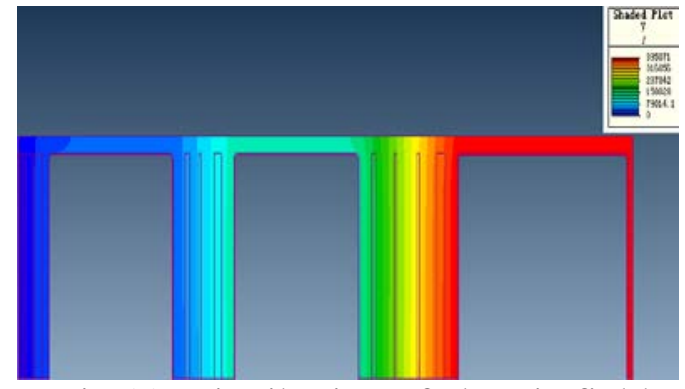

Fig.11. Distribution of electric field intensity in the middle part

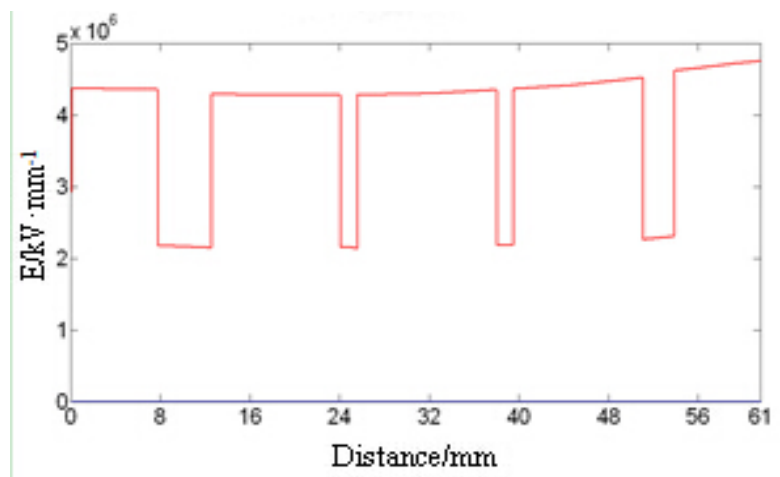

Fig.12. Distribution of field intensity along a path 4 between HV and MV winding

From Figure 10 and Figure 11, it can be seen the electric potential distribution between the inner surface of $\mathrm{HV}$ winding and the outer surface of MV winding is even, substantially, the intensity distribution of electric field is also uniform. The average intensity of electric field in the middle is nearly $4.02 \mathrm{kV} / \mathrm{mm}$, and the insulation margin is 6.5/4.02 $=1.51$. Take any path 4 between $\mathrm{HV}$ and MV winding, the distribution of electric field intensity is shown in Figure 12. Because the HV winding of power transformer is outgoing line, the average electric field intensity is greater. So the middle insulation between $\mathrm{HV}$ and MV winding is the major part of assessment.

D. Analysis on calculated results

According to the average field strength and insulation margin of typical path presented in Table 1 and the maximum field strength and corresponding insulation margin shown in the Table 2, it can be seen the requirements of field strength can be satisfied with the insulation margin in all power lines of different places.

Through the analysis of the data, the maximum field strength is in the corner of inner surface of the lowing pressure which is next to the upper part of the intermediate-voltage winding and the degree of its insulation margin is at 1.11. Although the maximum field strength in the central part is lower than the upper and lower, this power transformer is characterized with central outgoing line of $\mathrm{HV}$ winding, of which the field strength between $\mathrm{HV}$ and $\mathrm{MV}$ winding is relatively balanced. So the average field strength between $\mathrm{HV}$ and MV winding in the center is greater and the average field strength of typical paths chosen in this region is the maximum, which insulation margin is 1.51. Hence, the corner of all end windings in both upper and lower and the central electric field are all the crucial parts to be observed. 
Tab.1. Field strength and insulation margin of typical paths $(\mathrm{kV} / \mathrm{mm})$

\begin{tabular}{ccccc}
\hline Location of path & $\begin{array}{c}\text { Path } \\
\text { number }\end{array}$ & $\begin{array}{c}\text { Average field } \\
\text { strength }\end{array}$ & $\begin{array}{c}\text { Allowable } \\
\text { field strength }\end{array}$ & $\begin{array}{c}\text { Minimum } \\
\text { insulation margin }\end{array}$ \\
\hline $\begin{array}{c}\text { From MV end to MV end } \\
\text { of the lower }\end{array}$ & 1 & 2.23 & 6.5 & 2.91 \\
$\begin{array}{c}\text { From MV end to yoke of } \\
\text { the lower }\end{array}$ & 2 & 1.75 & 6.5 & 3.71 \\
$\begin{array}{c}\text { From MV end to LV end } \\
\text { of the lower }\end{array}$ & 3 & 1.89 & 6.5 & 3.44 \\
$\begin{array}{c}\text { From HV and MV of the } \\
\text { middle }\end{array}$ & 4 & 4.02 & 6.06 & 1.51 \\
\hline
\end{tabular}

Tab.2. Maximum field strength and insulation margin of all regions $(\mathrm{kV} / \mathrm{mm})$

\begin{tabular}{cccc}
\hline Region & $\begin{array}{c}\text { Maximum field } \\
\text { strength }\end{array}$ & $\begin{array}{c}\text { Maximum tolerated } \\
\text { field strength }\end{array}$ & $\begin{array}{c}\text { Insulation } \\
\text { margin }\end{array}$ \\
\hline The upper end & 7.68 & 8.5 & 1.11 \\
The lower end & 5.14 & 8.5 & 1.65 \\
The middle & 6.28 & 8.5 & 1.35 \\
\hline
\end{tabular}

\section{Conclusion}

The effectiveness of the mentioned method has been verified through comparing the calculation results in this paper with the experimental ones. As it can be summarized that the field intensity in the corner of LV close to the upper end of MV winding is maximum while its insulation margin is minimum, where should be the focus to be examined and studied. Furthermore, regions between $\mathrm{HV}$ and MV winding where average field strength is higher should also be mainly checked. The weakness of main insulation of entire transformer lies in the corner of the upper end of MV winding and the regions between $\mathrm{HV}$ and $\mathrm{MV}$ winding. The vulnerable position of main insulation is determined through the distribution of main insulation towards $220 \mathrm{kV}$ power transformer calculated in this paper, which could be an effective sample for the design of main insulation and optimized structure of products with the same type.

\section{Acknowledgement}

In this paper, the work was supported by NSFC, under Project No.51177103.

\section{References}

[1] Liu Fengying, Han Lei, Zhang Xile, Zhang Ping, Wang Haoming, Zhang Yumeng. Numerical analysis of main insulation electric field for power transformer [J].Journal of Tianjin Polytechnic University(in Chinese), 2014 33(3) 75-79.

[2] Wang Jianmin, Jing Chongyou, Fan Yana, et al. Numerical simulation of 3D stray field and short circuit impedance for a phase-shifting rectifier transformer [J], 2010. International Journal of Applied Electromagnetics and Mechanics,2010 33(1-2) 191-196.

[3] Gao Youhua, Gao Dan, Liyanbin, Gong Shuqiu, Wang Guogang. Improvement of main insulation structure for $110 \mathrm{kV}$ electric power transformer based on electric field analysis, IEEE International Conference on Electrical Mechines and Systems. 2008.

[4] Liu Jianjun, Li Yan. Calculation of Main Insulation Electric Field in 500kV Power Transformer with FEM [J] . TRANSFORMER(in Chinese),2008 45(9) 1-4

[5] Y Ebisawa, S Yamada, S mori, et al. DC creepage breakdown characteristics of oil-immersed 
Insulation [J]. IEEE Trans on Dielectric and Electrical Insulation. 2009.

[6] Li Yan, Zhu Lixun. Main Insulation Electric Field Calculation and Analysis Software for Power Transformer [J]. TRANSFORMER(in Chinese), 2013 50(6) 52-56. 